
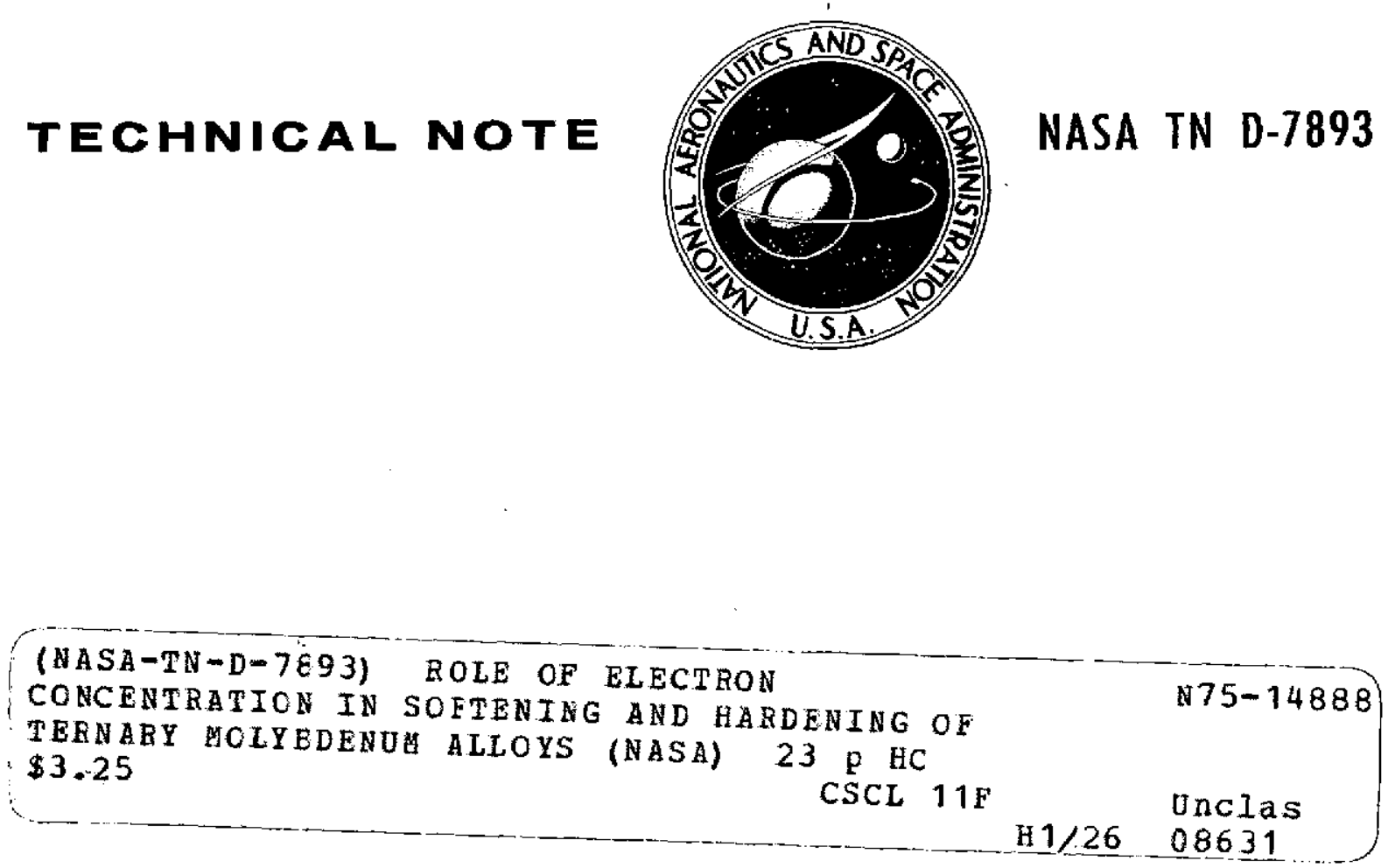

\title{
ROLE OF ELECTRON CONCENTRATION \\ IN SOFTENING AND HARDENING \\ OF TERNARY MOLYBDENUM ALLOYS
}

Joseph R. Stephens and Walter R. Witzke

Lewis Research Center

Cleveland, Obio 44135

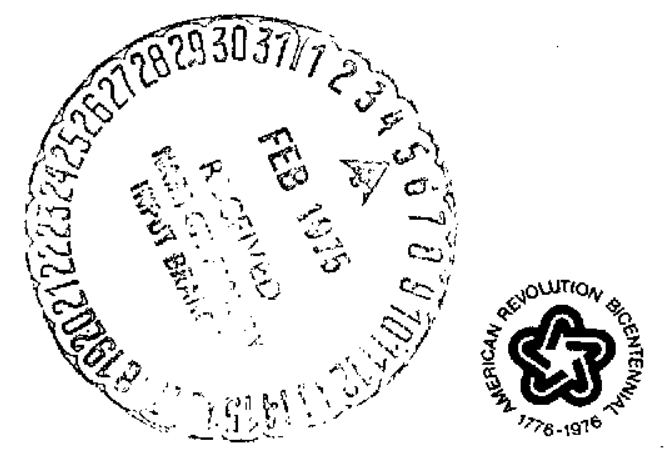

NATIONAL AERONAUTICS AND SPACE ADMINISTRATION - WASHINGTON, D. C. - JANUARY 1975 


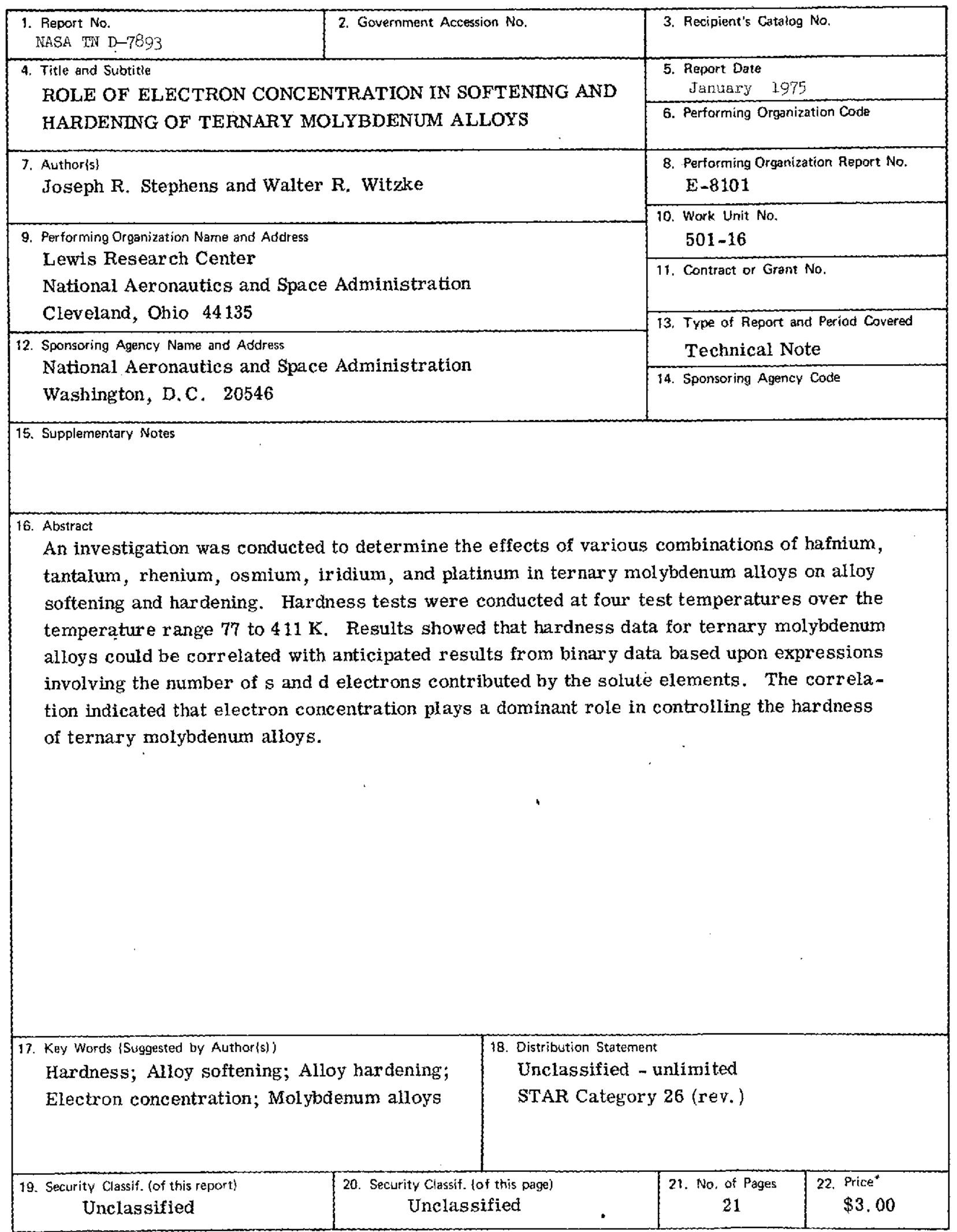

*For sale by the National Technical Infornation Service, Springfield, Virginia 22151 


\section{CONTENTS}

Page

SUMMARY .................................. 1

INTRODUCTION . . . . . . . . . . . . . . . . . . . . . . . . . . . 2

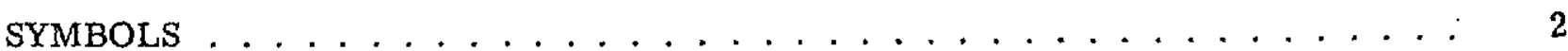

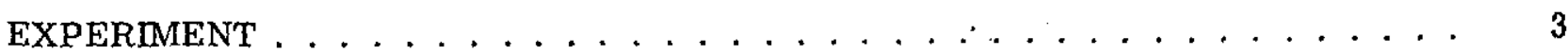

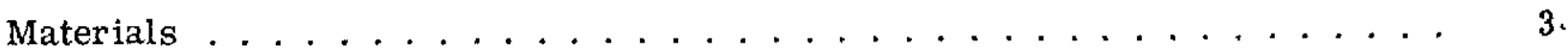

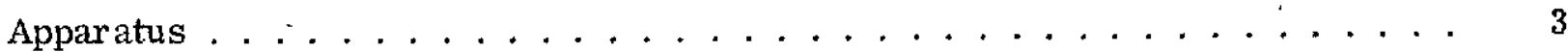

Procedure ............................ . . . . 3

RESULTS . . . . . . . . . . . . . . . . . . . . . . . . 4

Solute Effects ............................ . . . . . . 4

Temperature Effects . . . . . . . . . . . . . . . . . . . 5

Electron Concentration Effects . . . . . . . . . . . . . . . . 6

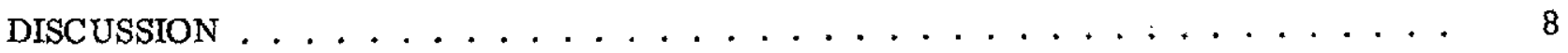

Correlation of Hardness With Electron Concentration . . . . . . . . . . . 8

Correlation of Physical Properties With Electron Concentration . . . . . . . . 9

CONCLUSIONS. . . . . . . . . . . . . . . . . . . . . . . . . 10

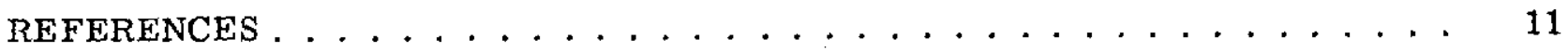

PRECEDING PAGE BLANK NOT FILMLD 


\title{
ROLE OF ELECTRON CONCENTRATION IN SOFTENING AND HARDENING OF TERNARY MOLYBDENUM ALLOYS

\author{
by.Joseph R. Stephens and Walter R. Witzke
} \\ Lewis Research Center
}

\author{
SUMMARY
}

An investigation was conducted to determine softening and hardening behavior in ternary Mo alloys and to correlate these effects with electron concentration in the alloys. Solute additions to molybdenum (Mo) involved combinations of hafnium, tantalum, rhenium, osmium, iridium, and platinum. Alloys were prepared by arc-melting highpurity electron-beam-melted Mo and high-purity alloying elements. Hardnesses were determined by means of a modified microhardness test unit over the temperature range 77 to $411 \mathrm{~K}$, which corresponds to the temperature range investigated in a previous study by the authors on binary Mo alloys and where alloy softening is normally observed for body-centered-cubic metals. A total of 66 ternary Mo alloys were studied at four test temperatures in order to characterize their hardness behavior and to permit a comparison with anticipated results based on binary Mo alloy data.

Results showed that hardness behavior of ternary Mo alloys could be correlated with results anticipated from binary data based upon expressions involving the number of $\mathrm{s}$ and $d$ electrons contributed by the solute elements. It was further shown that coimbining. alloying elements at concentrations that produce the maximum amount of softening in Mo does not result in additive softening in ternary Mo alloys. Once a critical electron concentration is exceeded, only alloy hardening is observed. A comparison of hardness be havior with literature data on Hall coefficient and magnetic susceptibility for tungstenrhenium alloys showed that the hardness minimums occur at the same rhenium concentrations where minimums are observed for the physical-property measurements. These observations and the correlation of hardness with electron concentration further support the hypothesis that alloy softening in group VI metals is an intrinsic characteristic of these metals and that electron concentration plays the dominant role in controlling hardness. 


\section{INTRODUCTION}

A previous investigation by the authors demonstrated that electron concentration plays the major role in determining the hardness of binary molybdenum alloys (ref. 1). Results showed that alloy hardening produced by additions of hafnium (Hf) and tantalum ( $\mathrm{Ta}$ ) to molybdenum (Mo) and alloy softening and hardening produced by additions of rhe nium ( $\mathrm{Re}$ ), osmium (Os), iridium ( $\mathrm{Ir}$ ), and platinum (Pt) to Mo could be correlated with the difference in the number of $s$ and d electrons of the solute element and Mo. These findings suggest that an intrinsic property of the alloys controls the hardness behavior of the Mo-base alloys investigated. If this argument is valid, it should be possible to predict the hardness behavior of ternary alloys on the basis of previously determined hardness data for binary alloys.

An alternative explanation of alloy softening is that solute elements can reduce the hardening effects associated with interstitial impurities by some form of substitutionalinterstitial association and thus soften the alloy. This hypothesis has grown out of the work on the group $\mathrm{V}$ metals Ta (refs. 2 and 3) and niobium (Nb) (refs. 4 and 5), where interstitial solubilities are very high relative to their solubilities in the group VI metals chromium (Cr), Mo, and tungsten (W). If solute-interstitial association is important in softening of group VI metals, prediction of hardness for ternary alloys from binary data might not be possible because of variations in interstitial content from alloy to alloy.

The primary purpose of this investigation was to characterize the hardness behavior of ternary Mo alloys and compare these results with those expected on the basis of binary hardness data. A secondary purpose of this investigation was to determine if softening observed in binary alloys was additive in ternary alloys when the solutes were combined at concentration levels producing maximum softening in binary alloys.

Alloy additions to Mo included various combinations of $\mathrm{Hf}, \mathrm{Ta}, \mathrm{Re}, \mathrm{Os}, \mathrm{Ir}$, and $\mathrm{Pt}$. Hardness, the primary experimental measurement for this study, was determined for each alloy at four test temperatures over a homologous temperature range of 0.02 to

$0.15 \mathrm{~T}_{\mathrm{m}}$ (where $\mathrm{T}_{\mathrm{m}}$ is the absolute melting temperature of unalloyed $\mathrm{Mo}$ ), the temperature range where alloy softening was observed for binary Mo alloys.

\section{SYMBOLS}

C solute content, at. \%

H hardness

R Hall coefficient

$\mathrm{T}_{\mathrm{m}}$ absolute melting temperature of unalloyed $\mathrm{Mo}$ 
$\Delta V$ difference in number of $s$ and $d$ electrons between solute and solvent

$$
\Delta V_{\mathrm{av}} \frac{\mathrm{C}_{1} \Delta \mathrm{V}_{1}+\mathrm{C}_{2} \Delta \mathrm{V}_{2}}{\mathrm{C}_{1}+\mathrm{C}_{2}}
$$

$\mathrm{X}_{\mathrm{R}} \quad$ residual paramagnetism

$\Omega \quad$ electron concentration parameter

\section{EXPERIMENT}

Materials

Materials for this investigation included high-purity electron-beam-melted Mo, Ta, and Re; commercial-purity Hf turnings and Pt foil; and hydrogen-annealed Os and Ir powders. Ingots were prepared by nonconsumable triple arc-melting of 70 -gram charges in a water-cooled copper mold followed by drop casting into a square-crosssection mold.

Table I presents analyzed compositions in atomic percent of the Mo alloys. Interstitial analyses of several alloys from each alloy series in ppm by weight are also listed in table $\mathrm{I}$.

Slices approximately 3 millimeters thick and 15 millimeters on a side were cut from the cast ingots for hardness testing. One face of each specimen that was to be used for hardness testing was given a metallographic polish. Specimens were then annealed in a vacuum of $1 \times 10^{-4}$. newton per square meter or better for 1 hour at 0.7 to $0.8 \mathrm{~T}_{\mathrm{m}}$ in order to reduce segregation and produce single-phase, equiaxed, strain-free specimens.

\section{Apparatus}

The modified microhardness test unit used in this study has been described previously (ref, 6). The test unit permitted hardness testing over the temperature range 77 to $411 \mathrm{~K}$.

\section{Procedure}

Molybdenum alloy compositions were selected to determine if softening observed in binary Mo alloys is additive when concentrations of the solutes producing maximum softening in binary alloys are combined to form ternary alloys. Solute combinations of this 
type included $\mathrm{Re}-\mathrm{Os}$, Re-Ir, Re-Pt, and Ir-Pt. Alloying elements that produce only hardening in binary Mo alloys also were combined with those elements that cause soft ening in Mo. These alloy combinations included Ir-Hf, Ta-Pt, Re-Hf, and Re-Ta. A third combination of solute elements consisted of those elements that were shown in the previous study to produce only hardening in Mo, namely, Hf and Ta. A total of 66 ternary alloys were investigated.

Test temperatures for ternary Mo alloys were selected to cover the temperature range where alloy softening was observed for the binary Mo alloys, that is, less than $0.17 \mathrm{~T}_{\mathrm{m}}$ ( $\mathrm{r}$ ef. 1). Test temperatures in equivalent increments included $77,188,300$, and $411 \mathrm{~K}$ or $0.027,0.065,0.104$, and $0.143 \mathrm{~T}_{\mathrm{m}}$, respectively. At least 10 diamond pyramid hardness impressions were made on each alloy at each test temperature. A load of 1 kilogram and a dwell time of 15 seconds were used for the impressions. The relative standard deviation was 5 percent.

\section{RESULTS}

\section{Solute Effects}

In order to determine if alloy softening observed in binary Mo alloys is additive, solute additions of $\mathrm{Os}, \mathrm{Ir}$, and $\mathrm{Pt}$ corresponding to those concentrations producing the maximum amount of softening at $77 \mathrm{~K}$ in the binary alloys were combined with $\mathrm{Re}$, which ranged in concentration from 2 to 23 atomic percent. Hardnesses for the ternary Mo alloys are summarized in table I.

Figure 1 shows the effect of Re on the hardnesses of the ternary alloys. Binary data for Mo-Re alloys are shown in figure 1 for comparison. The minimum hardnesses for Mo-Os, Mo-Ir, and Mo-Pt binary alloys at $77 \mathrm{~K}$ are also plotted on the ordinate in figure 1 to illustrate the softening achieved in binary alloys. It should be noted that the hardness increases with increasing Re content for three of the ternary systems investigated, which demonstrates that alloy softening is not additive.

Also shown in figure 1 are hardness data for a series of alloys containing Mo-6.5Ta-Re. (Concentrations are given in at. \%.) The hardness for another binary Mo alloy, Mo-7.9Ta, plotted on the ordinate, is near that obtained for the same Ta content in the ternary alloys. While Ta increases the hardness of Mo in binary alloys, combining a Mo-Ta alloy with Re produces softening in the ternary alloy system. It should be observed that the Mo-Ta-Re curve parallels the Mo-Re curve, the hardness minimum occurring at a $R$ e content of approximately 8 atomic percent for both alloy series.

A second comparison of hardening in binary and ternary alloys is shown in figure 2 for the Mo-Hf and Mo-8.5Re-Hf alloy series. The Re content is near the amount of Re producing the maximum amount of softening in the binary Mo-Re system. Only hardening 
is observed in this ternary system, and the two curves converge at higher Hf contents, which indicates that the hardening effect of Re is negligible in systems with high Hf contents.

A final form of hardness behavior in the ternary alloys is illustrated in figure 3 for Mo-3.5Ta-Pt alloys and Mo-6. 8Ta-Pt alloys compared with the binary Mo-Pt alloys. The curve is drawn through the binary data, and it can be seen that the ternary data, which are for alloys containing 2 to 5.5 atomic percent Pt, lie along the hardening portion of the curve independent of Ta content up to $6.8 \mathrm{Ta}$.

\section{Temperature Effects}

The variation of hardness with temperature for the ternary Mo alloys is shown in figures 4 to 6 . In figure 4 (a) the changes in hardness with temperature for unalloyed Mo and a binary Mo-1. 1Os alloy containing an amount of Os similar to that in the ternary alloys are compared with changes in hardness in the ternary Mo-0.960s-Re alloys. The temperature dependency of hardness for $\mathrm{Mo}$ is reduced upon alloying with Os. The ternary alloy curves are parallel to the binary alloy curves, and both have a much lower temperature dependency of hardness than unalloyed Mo. This behavior is also observed for the other two elements that produce softening in Mo combined with $\operatorname{Re}$ ( $\mathrm{Ir}$ and $\mathrm{Pt}$ ), as shown in figures $4(\mathrm{~b})$ and (c). In contrast, Ta added to Mo does not reduce the temper ature dependence of hardness for a Mo-7.9Ta alloy, as shown in figure 4(d). The ternary alloy Mo-6.5Ta-2.6Re exhibits a similar temperature dependency of hardness. However, when the Re content exceeds the Ta content as in the ternary Mo-6. 5Ta-7.8Re alloy, the variation of hardness with temperature is reduced substantially. The remaining ternary alloys in this series, with Re contents of 13.5, 18.5, and 22.8 atomic percent, also exhibit a reduced temperature dependency of hardness paralleling that of the Mo-6.5-Ta-7. 8Re alloy.

Figure 5 shows the variation of hardness with temperature of unalloyed Mo, a binary Mo-8.2Re alloy, and a series of ternary Mo-8.5Re-Hf alloys. Adding Re to Mo reduces the temperature dependency of hardness, and further additions of Hf result in a similar reduced temperature dependency of hardness for Hf contents ranging from 1.9 to 8.7 atomic percent.

In figure 6 ternary Mo-Ta-Pt alloys are compared with unalloyed Mo and two binary alloys, Mo-4.9Ta and Mo-4.8Pt. Unalloyed Mo and the Mo-4.9Ta alloy exhibit a similar variation of hardness with temperature, while the Mo-4.8Pt alloy and the ternary alloys exhibit slightly reduced temperature dependencies of hardness. 


\section{Electron Concentration Effects}

In a previous study by the authors ( $r$ ef. 1) on hardness behavior of binary Mo alloys, it was shown that hardness could be correlated with an electron concentration parameter $\Omega$, expressed by

$$
\Omega_{\text {binary }}=\mathrm{C}^{1 / 2} \Delta \mathrm{V}
$$

where $\mathrm{C}$ is the concentration of solute in atomic percent and $\Delta \mathrm{V}$ is the difference in number of $\mathrm{s}$ and $\mathrm{d}$ electrons between the solute element and Mo.

A schematic representation of the hardness behavior of binary Mo alloys at $77 \mathrm{~K}$ is shown in figure 7 as a function of $\Omega$. The figure is divided into the following three regions: A, characterized by hardening as a result of Ta or Hf additions; $B$, characterized by softening as a result of Re, Os, Ir, or Pt additions; and C, characterized by hardening as a result of larger additions of Re, Os, Ir, or Pt. The division between regions $\mathrm{B}$ and $\mathrm{C}$ corresponds to the hardness minimum and is temperature dependent. Values of the electron concentration parameter at the hardness minimum $\Omega$ min and the corresponding amounts of solute content in the binary Mo alloys (fig. 11 of ref. 1) for the four temperatures used in this study are as follows:

\begin{tabular}{|c|c|c|c|c|c|}
\hline \multirow[t]{2}{*}{$\begin{array}{c}\text { Test } \\
\text { temperature, } \\
\mathrm{K}\end{array}$} & \multirow{2}{*}{$\begin{array}{c}\text { Electron concentration } \\
\text { parameter at hard- } \\
\text { ness minimum, } \\
\Omega_{\text {min }}\end{array}$} & \multicolumn{4}{|c|}{$\begin{array}{l}\text { Solute content at } \\
\Omega_{\text {min }} \text {, at. } \%\end{array}$} \\
\hline & & $\operatorname{Re}$ & Os & $\mathrm{Ir}$ & $\mathrm{Pt}$ \\
\hline 77 & 2.7 & 7. 1 & 1. 8 & 0.8 & 0.5 \\
\hline 186 & 2.0 & 3.8 & 1.0 & .4 & .2 \\
\hline 300 & 1.2 & 1.5 & .4 & .2 & .1 \\
\hline 411 & .5 & .2 & .1 & .03 & .02 \\
\hline
\end{tabular}

Thus, binary alloy combinations that fall in region $B$ at lower temperatures may fall in region $C$ at higher temperatures because of the shift of region $B$ to lower values of $\Omega$ with increasing temperature.

To correlate the hardness of ternary alloys due to solute additions from the same region or from adjacent regions, the following expression was used:

$$
\Omega_{\text {ternary }}=\left(C_{1}+C_{2}\right)^{1 / 2} \Delta V_{a v}
$$


where

$$
\Delta V_{a v}=\frac{C_{1} \Delta V_{1}+C_{2} \Delta V_{2}}{C_{1}+C_{2}}
$$

There are a total of 11 possible combinations of $A, B$, and $C$ to form ternary alloys (see fig. 7(b)). Of these combinations, eight have been related to equation (2). The remaining three possible combinations of ternary alloys, which involve solute additions from each of the hardening regions $\mathrm{A}$ and $\mathrm{C}$, could not be correlated by equation (2), but could be described by equation (1), as is shown in this section.

Table I also summarizes the values of the difference in $\mathrm{s}$ and $\mathrm{d}$ electrons $\Delta \mathrm{V}_{\mathrm{av}}$, the electron concentration parameter $\Omega$, and the types of solute combinations for the ternary Mo alloys. Figure 8 shows the correlation of hardness with the square root of total sol ute content and the average electron concentration for the first group of eight types of solute combinations in the ternary Mo alloy systems, as described schematically in figure 7(a). The lines drawn are least-squares lines for the binary Mo alloys (ref. 1), so that a comparison can be made with the ternary-alloy data points. The ternary data are in good agreement with the hardness that would be anticipated from results for the binary alloys at each of the four test temperatures.

The remaining ternary alloys involve combinations of solutes from regions $\mathrm{A}$ and $\mathrm{C}$ in figure $7(\mathrm{a})$. Since these two areas represent hardening regions, softening would not be expected to occur in $\mathrm{A}+\mathrm{C}=\mathrm{B}$ type combinations. This was found to be true, and it was further observed that equation (2) also did not adequately describe the $\mathrm{A}+\mathrm{C}=\mathrm{A}$ or $\mathrm{A}+\mathrm{C}=\mathrm{C}$ combinations. Examination of figures 2 and 3 suggests that the contributions to hardness by Re in the Mo-Re-Hf system and the contributions by Ta in the Mo-Ta-Pt alloys which involve only $\mathrm{A}+\mathrm{C}$ combinations are essentially nil. This suggests that the ternary data can be correlated with $\Omega$ for Hf and Pt for these two series of ternary alloys. The remaining alloy system, Mo-Ta-Re, involving $\mathrm{A}+\mathrm{C}$ combinations followed a similar pattern.

Figure 9 shows the correlation of hardness with $\Omega$ at the four test temperatures for the $\mathrm{A}+\mathrm{C}$ alloys. The figure further shows that $\mathrm{A}+\mathrm{C}=\mathrm{A}$ combinations can be correlated with $\Omega$ for $\mathrm{Hf}$ or Ta while $\mathrm{A}+\mathrm{C}=\mathrm{B}$ or $\mathrm{A}+\mathrm{C}=\mathrm{C}$ combinations can be correlated with $\Omega$ for Pt or Re. The only exception to the previous correlations were the $\mathrm{A}+\mathrm{C}=\mathrm{A}$ alloys in the Mo-Ta-Pt system, which were better correlated with $\Omega$ for $\mathrm{Pt}$ but deviated from the least-squares line, as indicated by the solid data points in figure 9 . This deviation above the least-squares line is probably due to some hardening contributed by $\mathrm{Ta}$, which ranged in content from 8 to 36 atomic percent. 
Observation of figures 8 and 9 suggests that the value of $\Omega$ at the hardness minimum $\left(\Omega_{\mathrm{min}}\right)$ decreases with increasing test temperature in a manner that is similar to the re sults observed previously for binary Mo alloys (fig. 12 of ref. 1).

\section{DISCUSSION}

\section{Correlation of Hardness With Electron Concentration}

Hardness results for the ternary Mo alloys have further confirmed the importance of electron concentration in controlling the hardness of Mo alloys. This was particularly borne out by the combination of solute elements that produced softening in the binary Mo alloys. The results showed that for $\mathrm{B}+\mathrm{B}=\mathrm{B}$ combinations, behavior is additive and further softening is produced. However, if the critical electron concentration corresponding to the hardness minimum for binary alloy systems is exceeded in the ternary alloys, $B+B=C$, no further softening will occur and hardening begins. Ther efore, no additive softening effects were observed upon combining Re at a concentration which produced the maximum amount of softening in Mo with concentrations of Os, Ir, or Pt corresponding to solute contents at the hardness minimum.

The results further showed that there was good agreement between the measured hardnesses for ternary alloys and the hardnesses that would be expected from binary data. Electron concentration was shown to play a dominant role in controlling the hardness of the ternary Mo alloys by using equation (2), which averages the electron concentration contributed by each solute, and by taking into consideration the hardening and softening regions shown schematically in figure 7 . Solutes from the same or adjacent regions in figure 7 could be adequately described by equation (2), and the data were in good agreement with least-squares lines for the binary data.

In contrast, hardening produced by solutes from each of the two hardening regions could not be correlated by using equation (2). This was anticipated since equation (2) would predict ternary alloys formed by solutes from the two hardening regions falling in the softening region. However, only hardening would be expected in this type of ternary alloy. The hardness results could be correlated by using equation (1), which avoids the problem of placing the ternary alloys in the softening region. It is not understood why just one solute controls the hardness in these alloys; however, this behavior was observed in Mo-Ta-Re, Mo-Hf-Re, and Mo-Ta-Pt alloys. The correlation of hardness with electron concentration points to an intrinsic property controlling hardness in binary and ternary Mo alloys. This finding is in contrast with previous results obtained by the authors on $\mathrm{Nb}$ alloys ( $r$ ef. 5), where atom size misfit was observed to control hardness.

Most theories of solid solution strengthening contain an expression involving shear modulus and an atom size misfit parameter (ref. 7). More recently, attempts have been 
made to correlate hardening and softening with electron concentration. Stern (ref. 8) showed that solution hardening occurs in titanium ( $\mathrm{Ti}$ ) alloys predominantly by an electronic mechanism. In general, high hardening rates were produced in Ti alloys for which columns of the solute and solvents are far apart in the periodic table, that is, for which the difference in $s$ and $d$ electrons is great.

In addition, the results of reference 5 suggested a similar trend of increased hardening rates in $\mathrm{Nb}$ alloys with increase in periodic table group number of the solute el ement. However, atom size misfit played the major role in controlling the hardness of $\mathrm{Nb}$ alloys.

In previous studies on binary Mo alloys (ref. 1) electron concentration played the major role in controlling both alloy softening and alloy hardening. Again a trend of increased hardening rate with increasing difference in $\mathrm{s}$ and $\mathrm{d}$ electrons between solvent and solute was observed.

Finally, attempts were made by Leslie and coworkers to correlate iron (Fe) alloy toughness (ref. 9) and modulus (ref, 10) with number of s and d electrons. In general, an improvement in toughness was observed with increasing difference in the number of valence electrons between solute and solvent. Similarly, the modulus increased with the increase in difference of valence electrons between solute and Fe.

\section{Correlation of Physical Properties With Electron Concentration}

The results discussed in the last section suggest that electron concentration plays an important part in determining the mechanical properties of various metals and alloys, with possibly the most dominant role being found in alloys of the group VI metals. Of particular interest, of course, is the initial softening observed in $\mathrm{Cr}-\mathrm{Re}$ and $\mathrm{W}-\mathrm{Re}$ ( $r$ ef. 6); in Mo-Re, Mo-Os, Mo-Ir, and Mo-Pt (ref. 1); and in the ter nary Mo alloys of this study, which is followed by alloy hardening once a critical electron concentration has been reached. Some insight into the reason for this behavior may be gained by consideration of the work by Budagovskiy, Bykov, Gavrilyuk, and Podyachev (ref. 11). These researchers studied the W-Re system (up to 25 at. \% Re) by means of electrical resistivity, Hall effect, angular distribution of the annihilation of photons, and magnetic susceptibility.

Figure 10(a) is a comparison of hardnes's (ref. 6) and Hall coefficient ( $r$ ef. 11) of $\mathrm{W}-\mathrm{Re}$ alloys at $77 \mathrm{~K}$. It should be noted that the minimum in hardness and maximum in Hall coefficient occur at a Re content of approximately 8 atomic percent. Figure 10(b) is a similar comparison of hardness and magnetic susceptibility (residual paramagnetism) measurements at $300 \mathrm{~K}$ on $\mathrm{W}$-Re alloys. The hardness minimum and magnetic susceptibility maximum occur at approximately 5 atomic percent Re at this temperature. In contrast to the W-Re alloys, Nb-Mo alloys exhibit only alloy hardening (ref. 5), and 
as shown in figure 10(c), from the work of Jones, Pessall, and McQuillan (ref. 12), magnetic susceptibility decreases monotonically with increasing Re content.

The comparisons in figures $10(a)$ and (b) strongly suggest a direct correlation between mechanical properties (hardness) and electron structure, as indicated by the Hall coefficient and magnetic susceptibility. The abrupt change from softening to hardening in $\mathrm{W}-\mathrm{Re}$ alloys is reflected by a similar change in physical properties, which suggests a change in electronic structure occurs at a critical composition in the W-Re system. These correlations further support the contention that alloy softening and hardening of body-centered-cubic group VI metals are intrinsic properties of these metals and are controlled primarily by electronic structure.

In contrast, alloy hardening of body-centered-cubic group $\mathrm{V}$ metals is controlled by atomic size misfit, as shown by previous work by the authors on $\mathrm{Nb}$-base alloys (ref. 5). Alloy softening in these metals is apparently an extrinsic effect and, as suggested by others (refs. 2 to 4 ), is due to some type of solute-interstitial association.

\section{CONCLUSIONS}

Based on a hardness study of ternary alloys of molybdenum (Mo) with various combinations of hafnium (Hf), tantalum (Ta), rhenium (Re), osmium (Os), iridium (Ir), and platinum (Pt), the following conclusions are drawn:

1. Alloy softening observed in ternary Mo alloys (studied in this investigation) and in binary Mo alloys (studied previously by the authors) is a real characteristic of these alloys, as well as other group VI metals.

2. Alloy softening and hardening in ternary Mo alloys can, in general, be predicted from binary data by using expressions involving the number of $s$ and $d$ electrons contributed by the solute elements.

3. There is a critical electron concentration corresponding to the hardness minimum for all binary and ternary Mo alloys, which decreases with increasing test temperature. Combining solute elements $\mathrm{Re}, \mathrm{Os}, \mathrm{Ir}$, and $\mathrm{Pt}$ at concentrations that produce the $\max -$ imum amount of softening in Mo does not result in additive softening in ternary Mo alloys.

4. A direct correlation exists between hardness and electron structure for group VI metals. A comparison of hardness with literature data on Hall coefficient and magnetic susceptibility for W-Re alloys shows that the hardness minimums occur at the same Re concentrations where maximums are observed for Hall coefficient and magnetic susceptibility. 
5. The ability to predict the hardness of ternary Mo alloys from binary data and to correlate the data with the number of $s$ and d electrons suggests that extrinsic effects such as solute-interstitial interactions do not substantially affect the hardness of the Mo-base alloys.

Lewis Research Center,

National Aeronautics and Space Administration,

Cleveland, Ohio, October 29, 1974,

$506-16$.

\section{REFERENCES}

1. Stephens, Joseph R.; and Witzke, Walter R. : Alloy Hardening and Softening in Binary Molybdenum Alloys as Related to Electron Concentration. J. Less Common Metals, vol. 29, 1972, pp. 371-388.

2. Hasson, D. F.; and Arsenault, R. J.: Substitutional-Interstitial Interactions in BCC Alloys. Treatise in Materials Science and Technology, volume 1. H. Herman, ed., Academic Press, 1972, pp. 179-246.

3. Smialek, R. L.; Webb, G. L.; and Mitchell, T. E. : Solid Solution Softening in BCC Metal Alloys. Scripta Met., vol. 4, 1970, pp. 33-38.

4. Ravi, K. V.; and Gibala, R.: The Strength of Niobium-Oxygen Solid Solutions. Acta Met., vol. 18, no. 6, June 1970, pp. 623-634.

5. Stephens, Joseph R., and Witzke, Walter R.: Hardness Behavior of Binary and Ternary Niobium Alloys at 77 and 300 K. NASA TN D-7847, 1974.

6. Stephens, J. R.; and Witzke, W. R.: Alloy Softening in Group VIA Metals Alloyed With Rhenium. J. Less-Common Metals, vol. 23, 1971, pp. 325-342.

7. Leslie, W. C.: Iron and Its Dilute Substitutional Solid Solutions. Met. Trans., vol. 3, no. 1, Jan. 1972 , pp. 5-26.

8. Stern, E. A.: Application of Alloy Physics to Solution Strengthening. Presented at Materials Engineering Congress, Am. Soc. Metals, Oct. 1973.

9. Leslie, W. C.; Sober, R. J.; Babcock, S. G.; and Green, S. J.: Plastic Flow in Binary Substitutional Alloys of BCC Iron-Effects of Strain Rate, Temperature and Alloy Content. ASM Trans., vol. 62, no. 3, Sept. 1969, pp. 690-710. 
10. Speich, G. R.; Schwoeble, A. J. ; and Leslie, W. C. : Elastic Constants of Binary Iron-Base Alloys. Met. Trans., vol. 3, no. 8, Aug. 1972, pp. 2031-2037.

11. Budagovskiy, S. S.; Bykov, V. N. ; Gavrilyuk, M. I. ; and Podyachev, V. N. : Some Electron Structure Characteristics of W-Re Solid Solutions. Metallofiz, , no. 44,1973 , pp. 57-67.

12. Jones, D. W. ; Pessall, N. ; and McQuillan, A. D. : Correlation Between Magnetic Susceptibility and Hydrogen Solubility in Alloys of Early Transition Elements. Phil. Mag., vol. 6, no. 63, Mar. 1961, pp. 455-459. 
TARLF. 1. - SUMMARY OF HARDNESS DATA AND ELECTRON CONCENTRATION IELATIONS FOR TERNARY MOLYRDFNIM ALLOYS

\begin{tabular}{|c|c|c|c|c|c|c|c|c|c|c|c|c|c|c|c|c|}
\hline \multirow{2}{*}{\multicolumn{4}{|c|}{$\begin{array}{l}\text { Analyzed solute } \\
\text { content }\end{array}$}} & \multirow{2}{*}{\multicolumn{3}{|c|}{$\begin{array}{c}\text { Analyzed intersititial } \\
\text { content, } \\
\text { plmby wht. }\end{array}$}} & \multicolumn{4}{|c|}{ Tempcrature, $\mathrm{K}$} & \multirow{3}{*}{$\begin{array}{c}\text { Difference in } \\
\text { electron } \\
\text { roncentration, } \\
\Delta v_{\mathrm{av}}= \\
\frac{\mathrm{C}_{1} \Delta \mathrm{v}_{1}+\mathrm{C}_{2} \Delta \mathrm{v}_{2}}{\mathrm{C}_{1}+\mathrm{C}_{2}}\end{array}$} & \multirow{3}{*}{$\begin{array}{c}\text { Electron } \\
\text { concentration } \\
\text { parameter, } \\
\Omega_{\text {ternary }}= \\
\left.\left(\mathrm{C}_{1}+\mathrm{C}_{2}\right){ }\right)^{\prime} / \mathrm{v}_{\mathrm{av}} \\
(\mathrm{a})\end{array}$} & \multicolumn{4}{|c|}{ Temperature, $K$} \\
\hline & & & & & & & 77 & 188 & 300 & 411 & & & 77 & 188 & 300 & 411 \\
\hline at. $x$ & Solute & at. $\quad$ t & Solute & $\begin{array}{l}\text { Car- } \\
\text { bon }\end{array}$ & $\begin{array}{l}\text { Oxy- } \\
\text { gen }\end{array}$ & $\begin{array}{c}\text { Nitro- } \\
\text { gen }\end{array}$ & Vickers & 8 lıard & Inless I & numiker & & & Type a & of ternar & ry combin & ination \\
\hline 0.44 & $\mathrm{Re}$ & 0.23 & Os & 32 & .26 & 2 & 371 & 238 & 143 & 99 & 2. 34 & 1. 10 & $B+B=B$ & $\mathrm{~B}+\mathrm{B}-\mathrm{B}$ & $\mathrm{B}+\mathrm{B}=\mathrm{B}$ & $C+C=C$ \\
\hline .43 & & .52 & & --- & -- & -- & 342 & 225 & 150 & 135 & 1.48 & 1.48 & $\mathrm{~B}+\mathrm{B}-\mathrm{B}$ & $A, B=B$ & $B+C=\mathrm{B}$ & $c+c=c$ \\
\hline .96 & & .25 & & 30 & 28 & 2 & 352 & 229 & 138 & $\mathrm{t} 13$ & 1.21 & 1.33 & $\mathrm{~B}+\mathrm{B}=\mathrm{B}$ & $|B+B=B|$ & $\mathrm{B}+\mathrm{B}=\mathrm{B}$ & $\mathrm{C}+\mathrm{C}=\mathrm{C}$ \\
\hline 2.23 & & .96 & & -- & $-\cdot$ & -2 & 341 & 249 & 188 & 173 & 1.30 & 2.32 & $\mathrm{~B}+\mathrm{B}=\mathrm{B}$ & $B+B=C \mid$ & $c+c=c$ & $C+c=c$ \\
\hline 4.02 & & .32 & & 130 & 9 & 5 & 356 & 257 & 206 & 182 & 1.18 & 2. 64 & $\mathrm{~B}+\mathrm{B}-\mathrm{B}$ & $\mathrm{C}+\mathrm{B}-\mathrm{C} \mid$ & $\mathrm{C}+\mathrm{C}=\mathrm{C}$ & $\mathrm{C}+\mathrm{C}=\mathrm{C}$ \\
\hline a. 01 & & .95 & & --- &.-- & -- & 368 & 288 & 232 & 211 & 1.11 & 3. 31 & $\mathrm{C}+\mathrm{B}-\mathrm{C}$ & $|\mathrm{C}+\mathrm{B}=\mathrm{C}|$ & $\mathrm{C}+\mathrm{C}=\mathrm{C}$ & $C+C-C$ \\
\hline 12.19 & & .96 & &.- & $\cdots$ & -- & 378 & 315 & 250 & 228 & 1.07 & 3. 49 & $\mathrm{C}+\mathrm{B}=\mathrm{C}$ & $|C+B=C|$ & $\mathrm{C}+\mathrm{C}=\mathrm{C}$ & $\mathrm{C}+\mathrm{C} \cdot \mathrm{C}$ \\
\hline 16. $0 \mathrm{~B}$ & 1 & 1. 62 & 1 & $-\cdot$ & $-\infty$ & $\therefore$ & 429 & 358 & 309 & 267 & 1.09 & 4.59 & $\mathrm{C}+\mathrm{B}=\mathrm{C}$ & $C+C=C$ & $\mathrm{C}+\mathrm{C}=\mathrm{C} \mid$ & $C+C=C$ \\
\hline 2.23 & $\mathrm{Re}$ & 0.54 & Ir & $\cdots$ &.-- & -. & 362 & 268 & 212 & 186 & 1.39 & 2.31 & $\mathrm{~B}+\mathrm{R}=\mathrm{B}$ & $\mathrm{B}, \mathrm{C}=\mathrm{C}$ & $\mathrm{C} ; \mathrm{C}=\mathrm{C}$ & $\mathrm{C}+\mathrm{C}=\mathrm{C}$ \\
\hline 4.31 & & .56 & & 37 & G & 13 & 357 & 293 & 2.23 & 201 & 1.23 & 2. 71 & $B+B=C$ & $\mathrm{C}+\mathrm{C}=\mathrm{C}$ & $\mathrm{C}+\mathrm{C}=\mathrm{C}$ & $C+C=C$ \\
\hline B. 11 & & .58 & &.- & $\cdots$ & . & 366 & 304 & 232 & 230 & 1. 13 & 3.34 & $\mathrm{C}+\mathrm{B}=\mathrm{C}$ & $\mathrm{C}+\mathrm{C}=\mathrm{C} \mid$ & $C+C=C$ & $C+C=C$ \\
\hline 11.72 & & .60 & & -- & -- & -- & 411 & 344 & 265 & 237 & 1. 10 & 3.85 & $|\mathrm{C}+\mathrm{B}-\mathrm{C}|$ & $|c+c-c|$ & $\mathrm{C}_{1} \mathrm{C}=\mathrm{C}$ & $C+c-c \mid$ \\
\hline 15.79 & 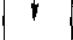 & 1.63 & 1 & --- & --- & $\cdots$ & $4 B D$ & 432 & 361 & 327 & 1. 19 & 4.95 & $\mathrm{C}+\mathrm{C}=\mathrm{C}$ & $\mathrm{C}+\mathrm{c}=\mathrm{C}$ & $c+c-c$ & $C+C=C$ \\
\hline 0.37 & $R_{t}$ & 0.35 & pt & 11 & 28 & $\cdots$ & 367 & 317 & 221 & 190 & 2.40 & 2.09 & $\mathrm{~B}+\mathrm{B}-\mathrm{B}$ & $B+C=C \mid$ & $\mathrm{B}+\mathrm{C}=\mathrm{C}$ & $B+C=C$ \\
\hline 2. 21 & & .47 & & --- & -- & -. & 385 & 290 & 234 & 201 & 1.53 & 2.50 & $\mathrm{~B}+\mathrm{C}-\mathrm{B}$ & $\mathrm{C}+\mathrm{C}-\mathrm{c}$ & $\mathrm{C}+\mathrm{C}=\mathrm{C}$ & $\mathrm{C}_{+} \mathrm{C}-\mathrm{C}$ \\
\hline 3.45 & & .57 & & -- & -- & 5 & 384 & 3.16 & 272 & 235 & 1.43 & 2. 86 & $\mathrm{~B}+\mathrm{C}=\mathrm{C}$ & $\mathrm{C}+\mathrm{C}=\mathrm{C}$ & $(c+C+c \mid$ & $\mathrm{C}+\mathrm{C}-\mathrm{C}$ \\
\hline 3.37 & & 1.08 & & .. & 150 & -- & 431 & 392 & 327 & 295 & 1. 73 & 3. 65 & $\mathrm{~B}+\mathrm{C}-\mathrm{C}$ & $\mathrm{C}+\mathrm{C}=\mathrm{C} \mid$ & $C, C=C$ & $\mathrm{C}+\mathrm{C}=\mathrm{C}$ \\
\hline 3. $8 B$ & & .45 & & 118 & 13 & 3 & 965 & 290 & 248 & 212 & 1.31 & 2.73 & $\mathrm{~B}+\mathrm{B}=\mathrm{C}$ & $\mathrm{C}+\mathrm{C}=\mathrm{C}$ & $\mathrm{C}+\mathrm{C}=\mathrm{C}$ & $\mathrm{C}_{1} \mathrm{C}=\mathrm{C}$ \\
\hline 7.37 & & 2. 15 & & 4 & 23 & -- & 592 & 560 & 459 & 421 & 1.68 & 5. 18 & $\mathrm{C}+\mathrm{C}-\mathrm{c} \mid$ & $\mathrm{C}+\mathrm{C}=\mathrm{C}$ & $\mathrm{C}+\mathrm{C}=\mathrm{C}$ & $\mathrm{C}+\mathrm{C}=\mathrm{C}$ \\
\hline 7.97 & & .46 & & $\ldots$ &.- & -- & 371 & 314 & 258 & 228 & 1. 16 & 3. $3 B$ & $\mathrm{C}+\mathrm{C}=\mathrm{C}$ & $|\mathrm{C}+\mathrm{C}-\mathrm{c}|$ & $\mathrm{C}+\mathrm{C}-\mathrm{C}$ & $\mathrm{C}+\mathrm{C}=\mathrm{C}$ \\
\hline 7,10 & & 1.21 & & 17 & 23 & 5 & 479 & 424 & 389 & 333 & 1.44 & 4. 14 & $\mathrm{~B}+\mathrm{C}=\mathrm{C}$ & $C+C=C \mid$ & $|\mathrm{C}+\mathrm{C}-\mathrm{C}|$ & $\mathrm{C}+\mathrm{C}=\mathrm{C}$ \\
\hline 11.83 & & 41 & & $=--$ & -- & - & 411 & 405 & 270 & 241 & 1.10 & 3.85 & $\mathrm{C}+\mathrm{B}=\mathrm{C}$ & $\mathrm{C}+\mathrm{C}=\mathrm{C}$ & $\mathrm{C}+\mathrm{C}=\mathrm{C}$ & $C+C=C$ \\
\hline 22.96 & 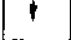 & 49 & $\gamma$ & 10 & 35 & 6 & 444 & $38 \mathrm{~J}$ & 311 & 284 & 1. $0 B$ & 5. 10 & $\mathrm{C}+\vec{B}=\mathrm{C}$ & $\mathrm{C}+\mathrm{C}=\mathrm{C}$ & $\mathrm{C}+\mathrm{C}-\mathrm{C}$ & $\mathrm{C}+\mathrm{C}-\mathrm{C}$ \\
\hline 0.45 & $\operatorname{Ir}$ & 0.51 & IIf & --- & $\cdots$ & $\cdots$ & 355 & 269 & 220 & 188 & 0.34 & 0.34 & $B+A=B$ & $C+A=B$ & $C+A=B$ & $C+A-K$ \\
\hline 0.10 & $\mathrm{Ir}$ & 0.15 & $p_{t}$ & 96 &.- & $\cdots$ & 348 & 248 & 185 & 162 & 3.60 & 1. 80 & $\mathrm{~B}+\mathrm{B}-\mathrm{B}$ & $\mathrm{B} \uparrow \mathrm{B}=\mathrm{B}$ & $\mathrm{B}+\mathrm{C}=\mathrm{C}$ & $C+C=C$ \\
\hline .16 & & .77 & & $-\cdots$ & 32 & -. & 396 & 367 & 297 & 257. & 3. 83 & 3.69 & $\mathrm{~B}+\mathrm{C}=\mathrm{C}$ & $|\mathrm{B}+\mathrm{C}-\mathrm{C}|$ & $\mathrm{B}+\mathrm{C}-\mathrm{C}$ & $\mathrm{C} \& \mathrm{C}=\mathrm{C}$ \\
\hline .29 & & 1.83 & & $\cdots$ & -- & 1 & 508 & 507 & 466 & $419^{\circ}$ & 3. 86 & 5.62 & $B+C=C$ & $B+C-C \mid$ & $C_{1} C=c$ & $C+C=C$ \\
\hline .48 & & 3.85 & & 37 & --- & -- & 792 & 727 & 636 & 593 & 3.89 & 8.09 & $\mathrm{~B}+\mathrm{C}=\mathrm{C}$ & $|\mathrm{C}+\mathrm{C}-\mathrm{C}|$ & $\mathrm{C}+\mathrm{C}+\mathrm{C}$ & $C+C=C$ \\
\hline .19 & & .29 & & $\cdots$ & 25 & -- & 366 & 281 & 236 & 196 & 3.60 & 2,50 & $\mathrm{~B}, \mathrm{D}=\mathrm{B}$ & $B+C=C$ & $C+C=c$ & $\mathrm{C}+\mathrm{C}=\mathrm{C}$ \\
\hline .66 & & .42 & & 105 & 13 & 7 & 418 & 349 & 286 & 265 & 3.39 & 3.52 & $\mathrm{~B}+\mathrm{B}=\mathrm{C}$ & $\mathrm{C}+\mathrm{C}-\mathrm{C}$ & $\mathrm{C}+\mathrm{C}=\mathrm{C}$ & $C_{1} C=C$ \\
\hline .60 & & .11 & & 30 & $2 \hat{~}$ & 2 & 373 & 297 & 235 & 20.9 & 3.15 & 2. 66 & $B, B=D$ & $C+\mathrm{B}=\mathrm{C} \mid$ & $\mathrm{C}+\mathrm{C}=\mathrm{C}$ & $\mathrm{C}+\mathrm{C}=\mathrm{C}$ \\
\hline 1.20 & & .08 & & 18 & 24 & 2 & 458 & 349 & 288 & 260 & 3.06 & 3.46 & $\mathrm{C}+\mathrm{B}=\mathrm{C}$ & $\mathrm{C}+\mathrm{B}=\mathrm{C}$ & $\left|c+R_{i}=c\right|$ & $\mathrm{C}+\mathrm{C}=\mathrm{C}$ \\
\hline 1,83 & 1 & 1.05 & 1 & $\ldots$ & $\cdots$ & -- & 596 & 534 & 481 & 444 & 3. 36 & 5. 71 & $\mathrm{C}+\mathrm{C}=\mathrm{C}$ & $\mathrm{C}+\mathrm{C}=\mathrm{C})$ & $C+C=c \mid$ & $C \cdot C=C$ \\
\hline 0.54 & $\mathrm{Ta}$ & 0.50 & Pt &.- & -- & -- & 377 & 284 & 236 & 174 & 1.40 & 1.43 & $A+C-B$ & $A+C=B$ & $A+C=C$ & $\Lambda+C=C$ \\
\hline 1.81 & & .79 & & 21 & 25 & 4 & 440 & 351 & 295 & 263 & .50 & .81 & $A+C=B$ & $\mathrm{~A}+\mathrm{C}=\mathrm{B}$ & $A+C=B$ & $A+C-C$ \\
\hline 1.87 & & .74 & & 21 & 32 & -- & 434 & 400 & 303 & 283 & .42 & .67 & $A+C=B$ & $A+C=B$ & $A+C=B$ & $A+C=B$ \\
\hline 3.37 & & 2.04 & & --- & 6 & -- & 561 & 473 & 415 & 376 & .89 & 2.00 & $A+C=B$ & $|A+C=B|$ & $A, C-B$ & $A+C=C$ \\
\hline 3.01 & & 3. 14 & & --- & 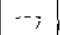 & I & 686 & 643 & 542 & 475 & 1.33 & 3.44 & $A+C=B$ & $\mathrm{~A}+\mathrm{C}=\mathrm{B}$ & $\mathrm{A}+\mathrm{C}-\mathrm{C}$ & $A+C=C$ \\
\hline 3.47 & & 4. 15 & & 21 & 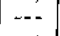 & -- & 776 & 675 & 620 & 551 & 1. 72 & 4.76 & $A+C=B$ & $A+C=B$ & $\Lambda+C=C$ & $A+C=C$ \\
\hline 8. 02 & & 1. 63 & & $\ldots-$ & 6 & -- & 587 & 485 & 432 & 383 & .16 & -.48 & $|A+C=A|$ & $A+C=A$ & $A, C=A$ & $A+C=A$ \\
\hline 6.87 & & 2.95 & & -. & 18 & -- & 645 & 559 & 529 & 458 & .50 & 1,57 & $A, C=B$ & $A+C=B$ & $A+C=B$ & $A+C \div C$ \\
\hline 6.73 & & 3.86 & & -. & -.- & 1 & 779 & 683 & 649 & 577 & .82 & 2. 68 & $A+C=B$ & $\mathrm{~A}_{1} \mathrm{C}=\mathrm{B}$ & $A+C=B$ & $A+C=C$ \\
\hline 6.78 & & 5.38 & & 11 & $\cdots$ & - & 832 & 808 & 710 & 675 & 1.21 & 4.23 & $A+C=B$ & $A+C-B$ & $A, C=\mathrm{B}$ & $A+C=C$ \\
\hline 9.35 & & 1. 70 & & $\ldots$ & -- & 1 & 579 & 492 & 422 & 384 & .23 & -.73 & $A+C=A$ & $\Lambda+C=A$ & $A+C-A$ & $A+C \sim A$ \\
\hline 12.25 & & 2.95 & &.- & 11 & -- & 748 & 668 & 596 & 545 & .20 & -. 75 & $A+C=A$ & $A+C=A$ & $A+C=A$ & $A+C \rightarrow A$ \\
\hline 15,04 & & .92 & & 12 & 18 & 4 & 573 & 489 & 422 & 371 & .71 & $-2 . B A$ & $A+C=A$ & $A+C+A$ & $A_{1} C=A$ & $A+C=A$ \\
\hline 16.06 & & 1. 15 & & 11 & -.- & - & 559 & 470 & 405 & 358 & .67 & -2.76 & $A+C=A$ & $A+C=A$ & $A+C=A$ & $A+C=A$ \\
\hline 20.70 & & 2. $3 a$ & &.-- & $\cdots$ & 1 & 719 & 668 & 606 & 555 & 38 & -1.83 & $A+C=A \mid$ & $\Lambda+C=A$ & $A+C-A$ & $A+C=A$ \\
\hline 36.86 & $\dagger$ & 2. 91 & 1 & 17 & --- & -- & 701 & 655 & 600 & 545 & .65 & -4.07 & $\mathrm{~A}+\mathrm{C}-\mathrm{A}$ & $\mathrm{A}+\mathrm{C}=\mathrm{A}$ & $A+C=A$ & $A+C=A$ \\
\hline 0.56 & $\mathrm{Ta}$ & 0.46 & $\mathrm{Hf}$ & --- & 449 & - & 421 & 268 & 175 & 135 & -1.45 & $-1,47$ & $A \perp A=A$ & $A+A \rightarrow A$ & $\Lambda+\mathrm{A}=\mathrm{A}$ & $A+A=A$ \\
\hline 1.04 & & 1.14 & & 18 & 26 & 4 & 447 & 283 & 194 & 175 & -1.52 & -2.25 & & & & \\
\hline 1.00 & & f. 30 & & 33 & 26 & 8 & 533 & 444 & 359 & 335 & -1.86 & -5.01 & & & & $y$ \\
\hline 10.80 & 1 & 10.99 & $t$ & 49 & -.. & -- & 650 & 559 & 498 & 481 & -1.50 & -7.02 & $\phi$ & & $\downarrow$ & 1 \\
\hline 0.46 & He & 4.68 & $\mathrm{HF}$ & 44 & -- & -- & 476 & 373 & 293 & 290 & -1.73 & -3.93 & $\mathrm{~B}+\mathrm{A}=\mathrm{A}$ & $B: A=A$ & $B+A=A$ & $C+A-A$ \\
\hline 1. 00 & & 9.47 & & $-n$ & -- & -- & 583 & 494 & 435 & 426 & -1.71 & -5.54 & $B+A=A$ & $B+\Lambda=A$ & $(\mathrm{C}+\mathrm{A}-\mathrm{A})$ & $C: A=A$ \\
\hline 1.91 & & .12 & & $\cdots$ & -- & 2 & 366 & 248 & 145 & 118 & .92 & 1.17 & $\mathrm{~B}+\mathrm{A}=\mathrm{B}$ & $C+A \rightarrow B$ & $\mathrm{C}+\mathrm{A}=\mathrm{B}$ & $C+A=C$ \\
\hline 4. 18 & & .28 & & $\cdots$ & --- & -- & 343 & 234 & 161 & 145 & .81 & 1. 71 & $\mathrm{~B}+\mathrm{A}=\mathrm{B}$ & $C+\Lambda=R$ & $\mathrm{C}+\mathrm{A}=\mathrm{C}$ & $C+A=C$ \\
\hline B. 58 & & 1.93 & & $\cdots$ & $\cdots$ & $\cdots$ & 396 & 308 & 260 & 2.35 & .45 & 1. 46 & $\mathrm{C}+\mathrm{B}=\mathrm{B}$ & $C+A=B$ & $\mathrm{C}+\mathrm{A}=\mathrm{C}\}$ & $C+A-C$ \\
\hline B. 50 & & 3. 72 & & 92 & 23 & 2 & 443 & 357 & 299 & 272 & -.09 & -30 & $C+\Lambda=\mathrm{A}$ & $\mathrm{C}+\mathrm{A}-\mathrm{A}$ & $C+A=A$ & $C+A-A$ \\
\hline B. 64 & & 6. 33 & & 16 & 19 & -- & 524 & 430 & 401 & 354 & -.27 & -1.04 & $|\mathrm{C}+\mathrm{A}-\mathrm{A}|$ & $C+A=A$ & $\mathrm{C}+\mathrm{A}=\mathrm{A}$ & $C+A=A$ \\
\hline 8.43 & 1 & 8. 73 & t & -- & -- & - & 583 & 500 & 4.36 & 40.3 & -.53 & -2.18 & $C+A-A)$ & $C+A=A$ & $C+A=A\}$ & $C+A=A$ \\
\hline 2.64 & $\mathrm{Re}$ & 6. 18 & Tu & 14 & 27 & -- & 424 & 308 & 203 & 187 & -0.40 & $-1,19$ & $B+A=A$ & $\mathrm{C}+\Lambda=\mathrm{A}$ & $(\mathrm{C}+\mathrm{A}-\mathrm{A} \mid$ & $C+A=A$ \\
\hline $7.8 \mathrm{~J}$ & & 7.02 & & 12 & 133 & -- & 386 & 313 & 246 & 228 & .05 & .21 & $C+\Lambda=B$ & $C+A=B$ & $C: A=B$ & $C+\Lambda=B$ \\
\hline 13.48 & & 6.42 & & $\cdots$ & -- & -- & 413 & 344 & 306 & 269 & .35 & 1. 58 & $\mathrm{C}+\mathrm{A}=\mathrm{B}$ & $C+A=B$ & $C+A=C\}$ & $C \cdot A=C$ \\
\hline 18.47 & & c. 35 & & 52 & 23 & -- & 450 & 383 & 329 & 291 & .49 & 2.43 & $\mathrm{C}+\mathrm{A}=\mathrm{B}$ & $\mathrm{C}+\mathrm{A}=\mathrm{C} \mid$ & $\mathrm{C}+\lambda=\mathrm{C}$ & $\mathrm{C}+\mathrm{A}=\mathrm{C}$ \\
\hline 22.82 & & 6.70 & $t$ & --- & $\cdots$ & -- & 462 & 409 & 348 & 307 & .55 & 2.97 & $C+A=C$ & $C+A=C$ & {$[C+A=C]$} & $C+A=C$ \\
\hline
\end{tabular}

$a_{\text {For all A }}+\mathrm{C}$ combinations $\Omega_{\text {binary }}$ was used rather than $\Omega_{\text {ternary }}$. 


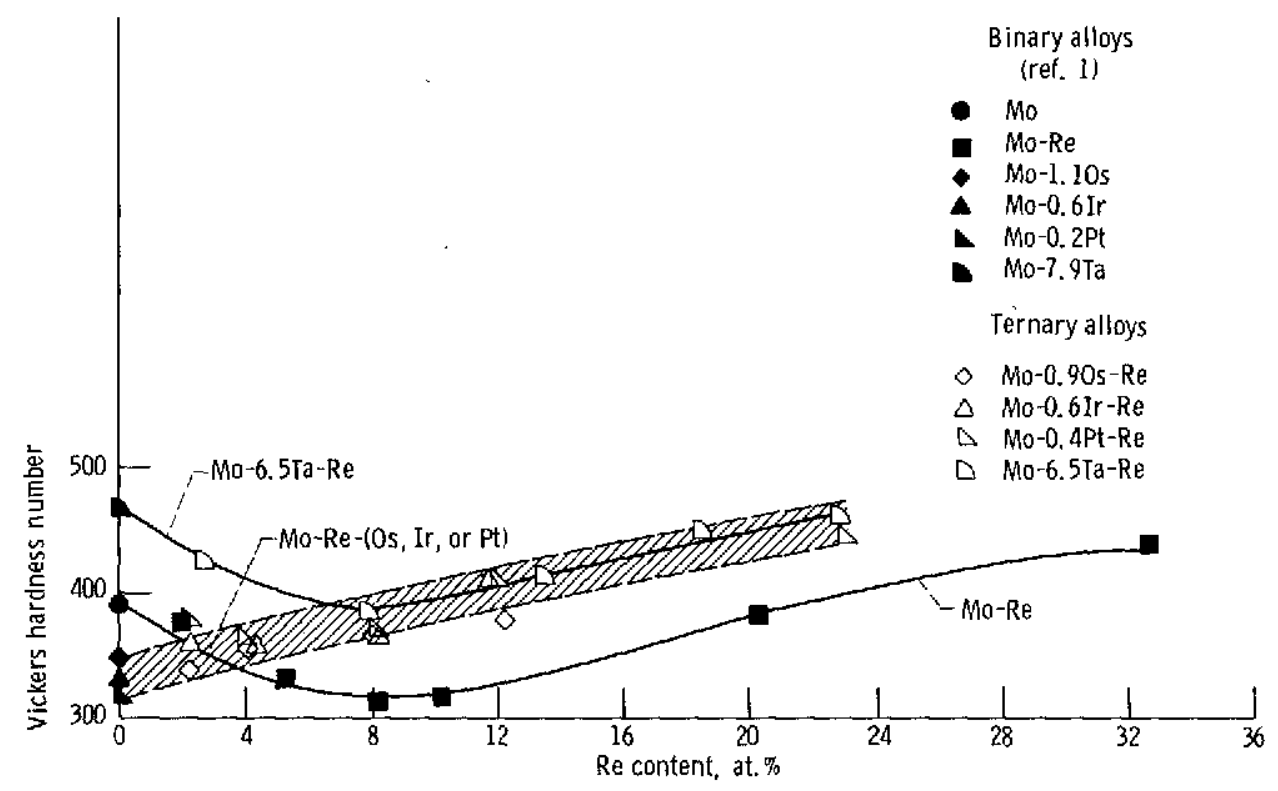

Figure 1. - Effect of Re on hardness in ternary Mo-base alloys at $77 \mathrm{~K}$.

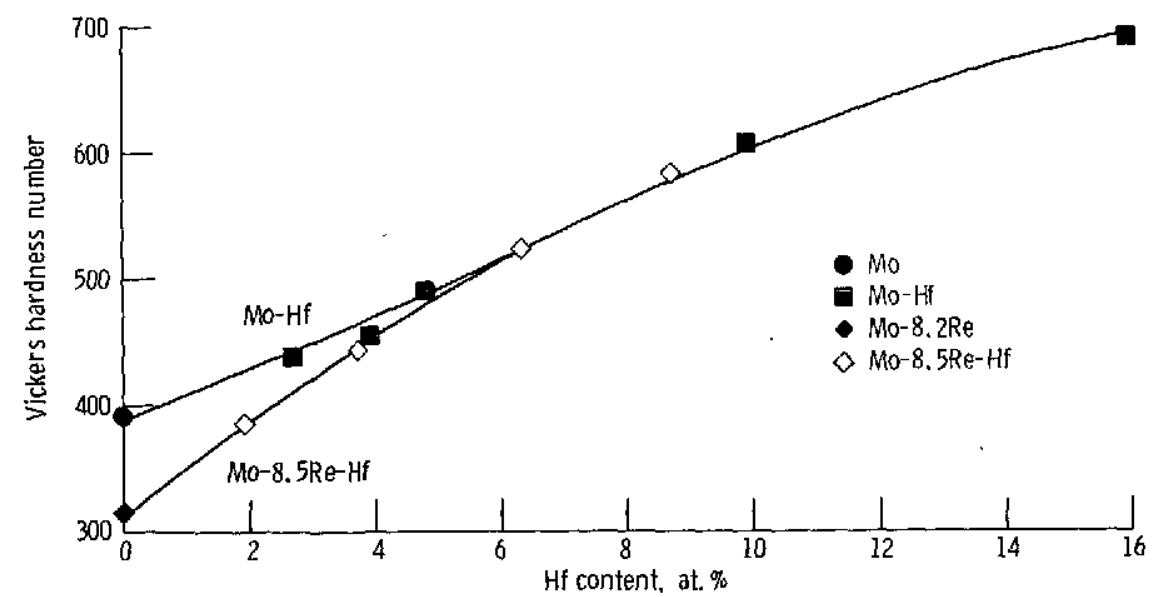

Figure 2. - Effect of $\mathrm{Hf}$ on hardness at $77 \mathrm{~K}$ in binary Mo-Hf alloys and ter nary Mo-8. 5Re-Hf alloys. 


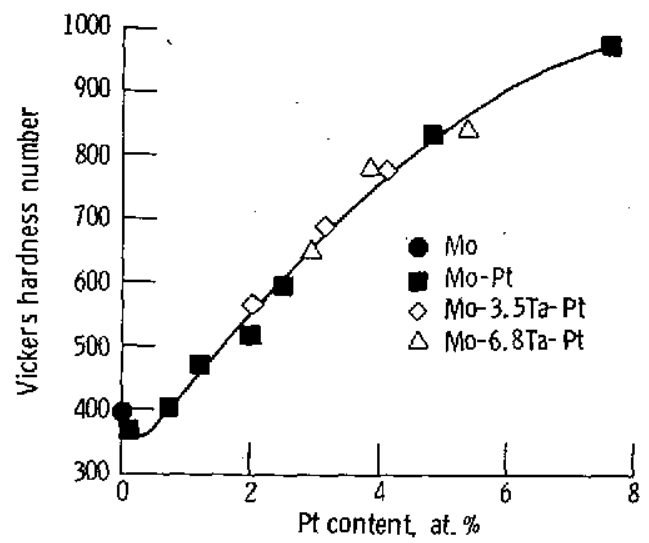

Figure 3. - Effect of Pt on hardness at $77 \mathrm{~K}$ in binary Mo-Pt alloys and in ternary Mo-3.5 Ta-Pt and Mo-6.8Ta-Pt alioys.

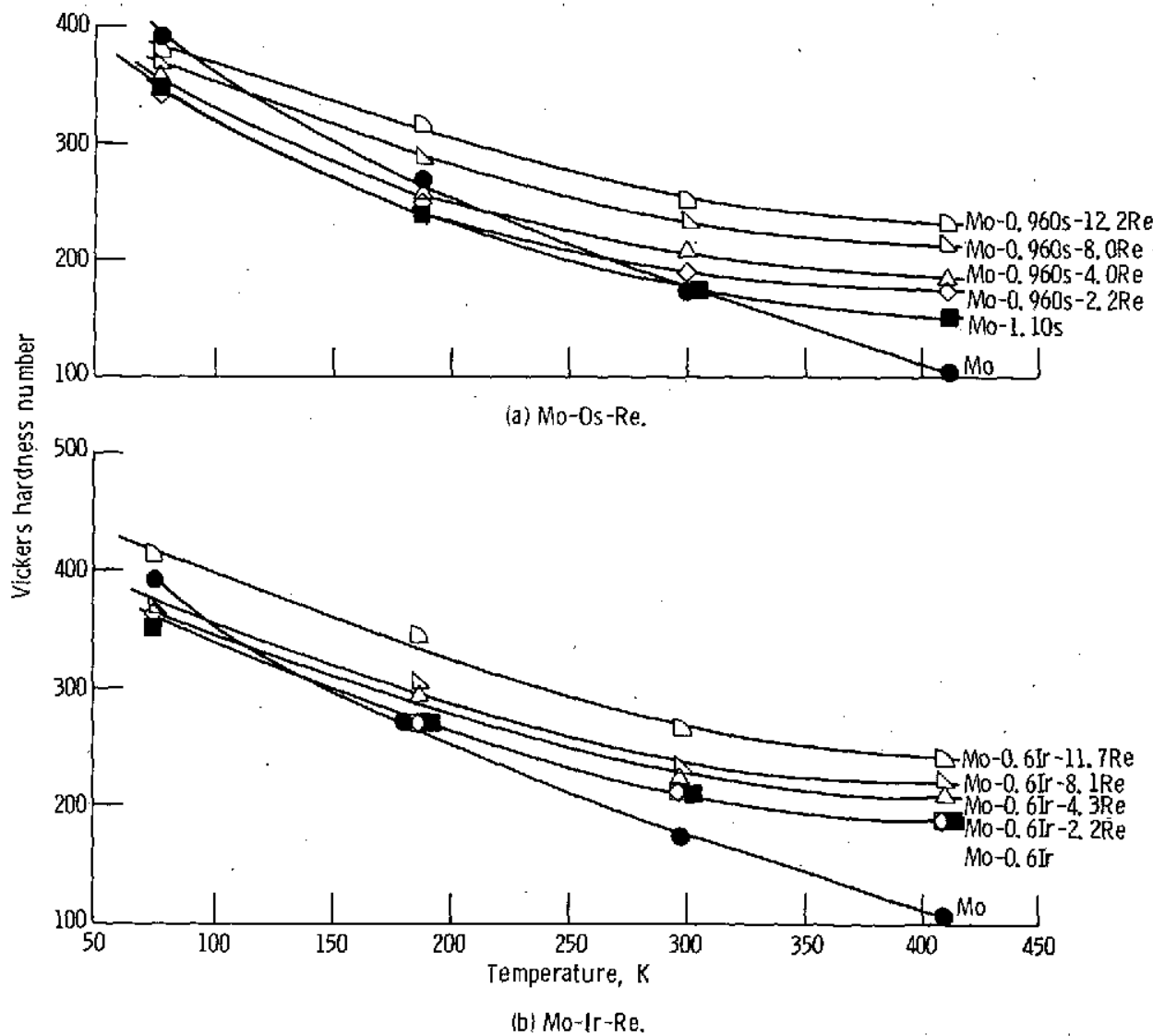

Figure 4. - Effect of temperature on hardness of ternary Mo-Os-Re, Mo-Ir-Re, Mo-Pt-Re, and Mo-Ta-Re alloys. 


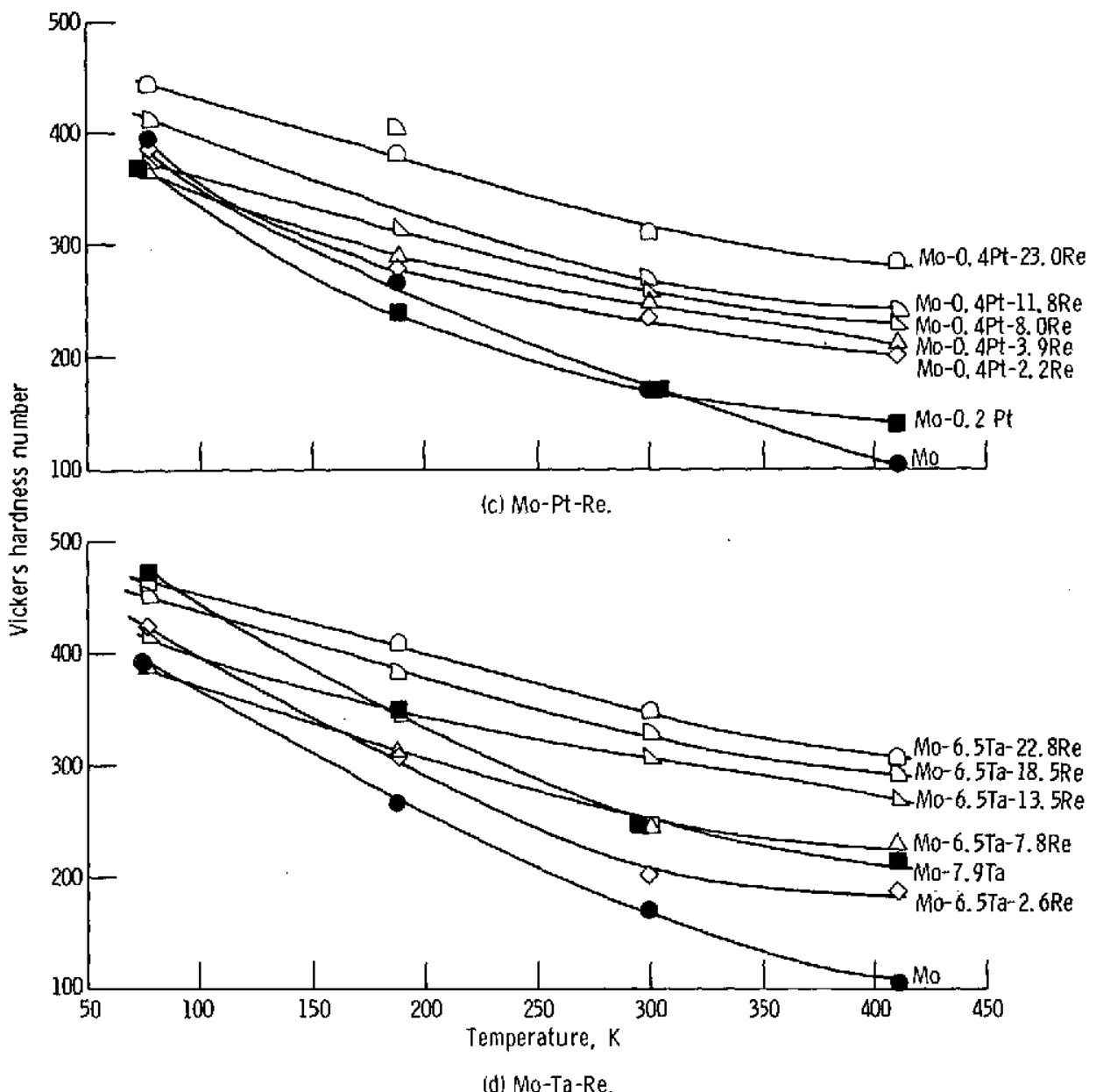

Figure 4. - Concluded.

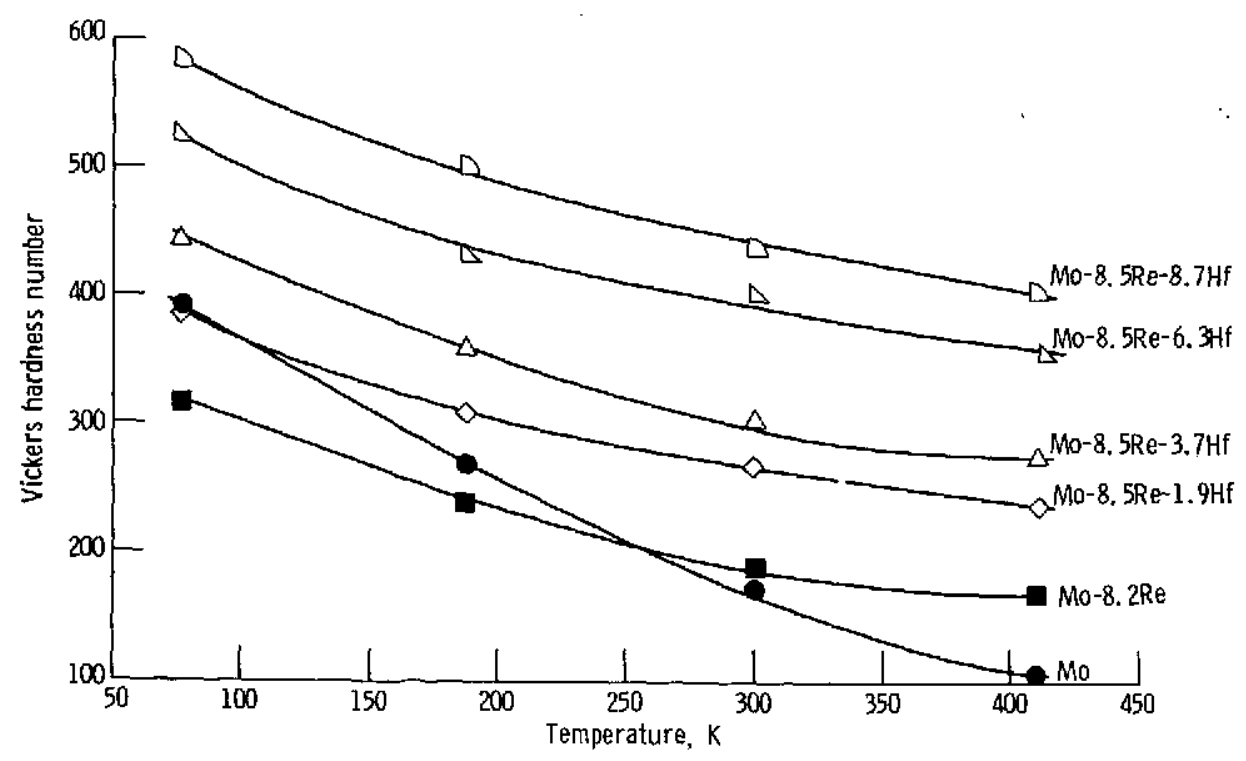

Figure 5. - Effect of temperature on hardness of ternary Mo-Re-Hf alloys. 


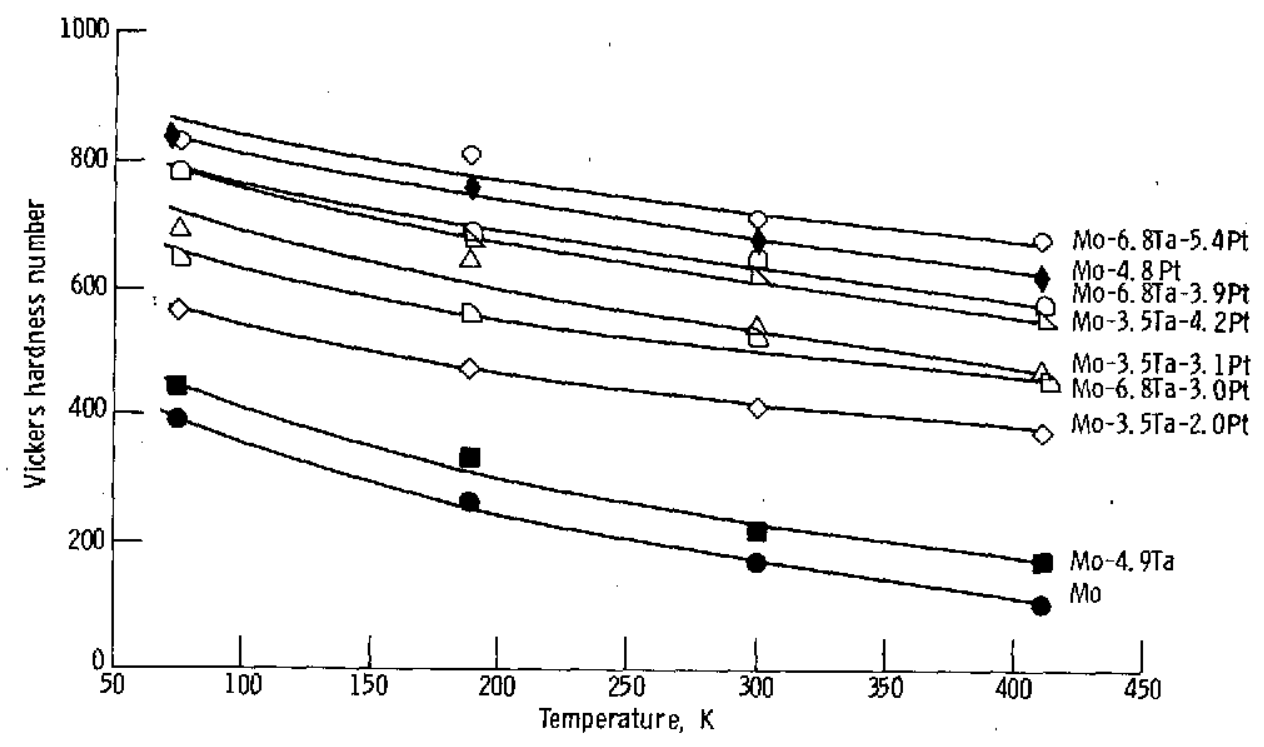

Figure 6. - Effect of temperature on hardness of ternary Mo-Ta-Pt alloys.

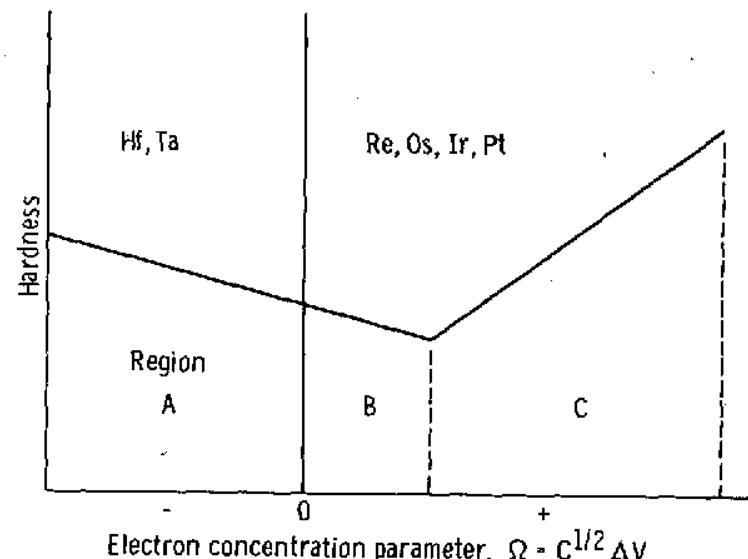

(a) Schematic of binary data.

\begin{tabular}{|l|l|}
\hline $\begin{array}{l}\text { Correlated } \\
\text { by eq. (2) }\end{array}$ & $\begin{array}{l}\text { Correlated } \\
\text { by eq. (1) }\end{array}$ \\
\hline$A+A=A$ & $A+C=A$ \\
$B+B=B$ & $A+C=B$ \\
$C+C=C$ & $A+C=C$ \\
$A+B=A$ & \\
$A+B=B$ & \\
$B+B=C$ & \\
$B+C=B$ & \\
$B+C=C$ & \\
\hline
\end{tabular}

(b) Possible ternary alloy combinations.

Figure 7. - Schematic representation of binary Mo data and possible ternary alloy combinations. 


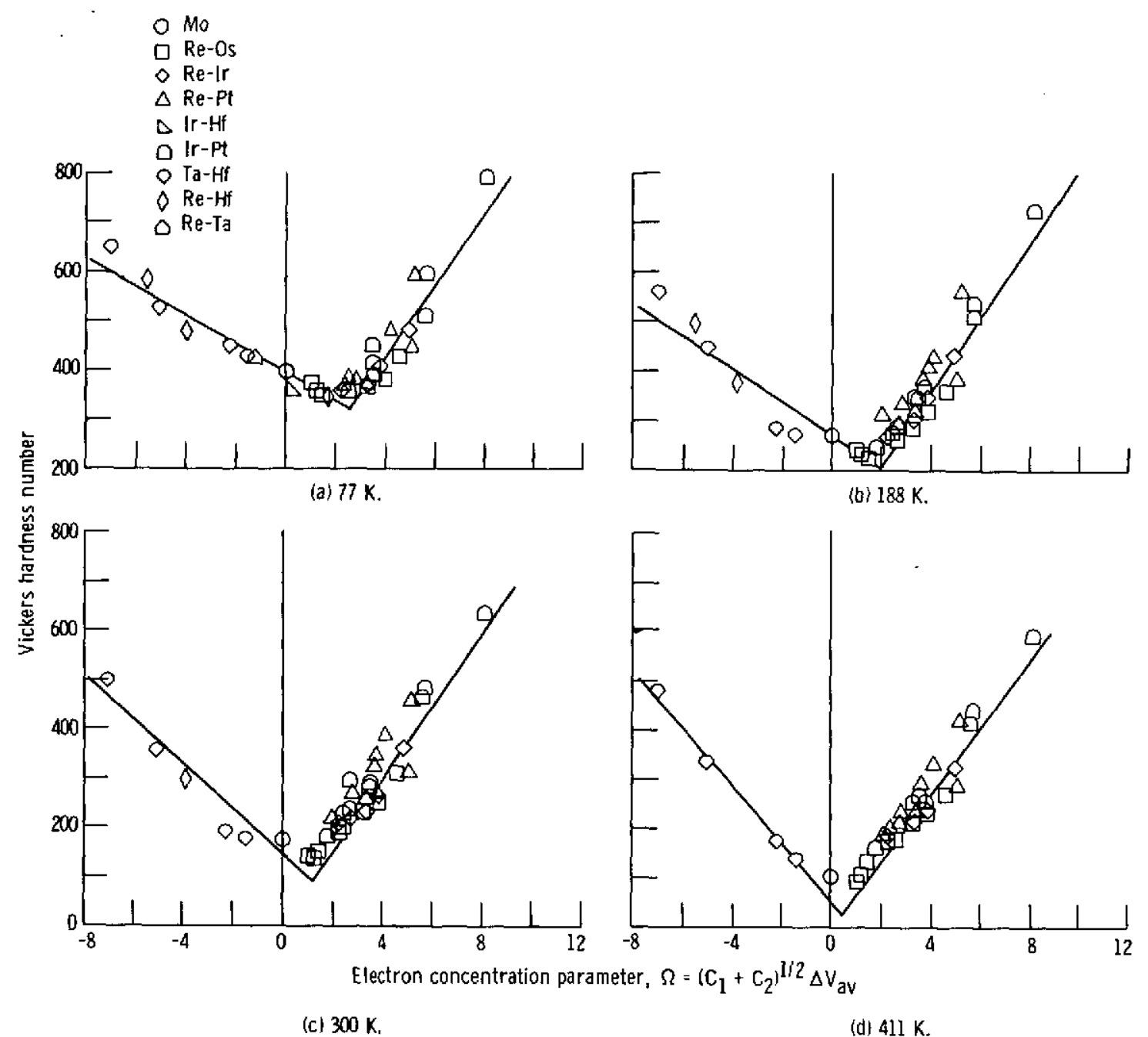

Figure 8. - Correlation of hardness of ternary Mo alloys with square root of total solute content and average difference in number of $s$ and $d$ electrons. 


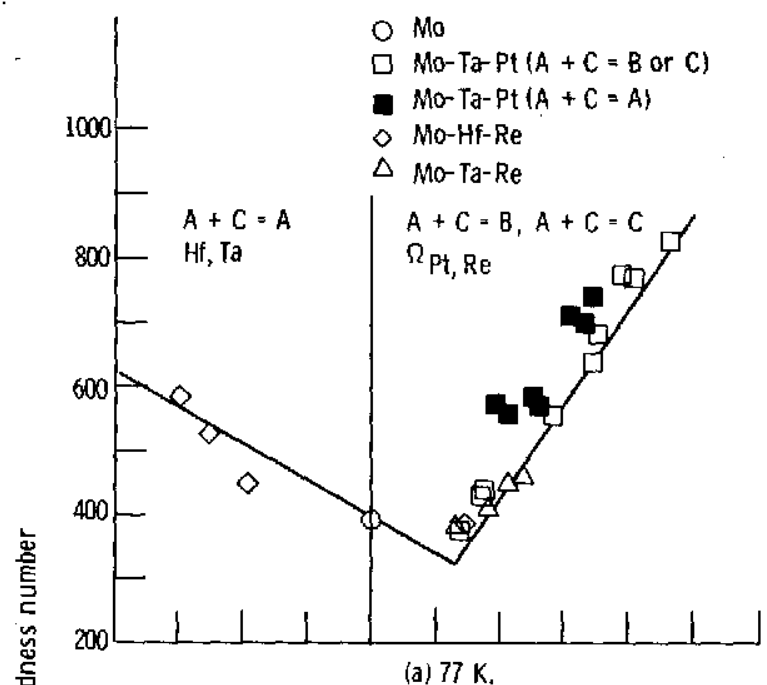

(a) $77 \mathrm{~K}$.

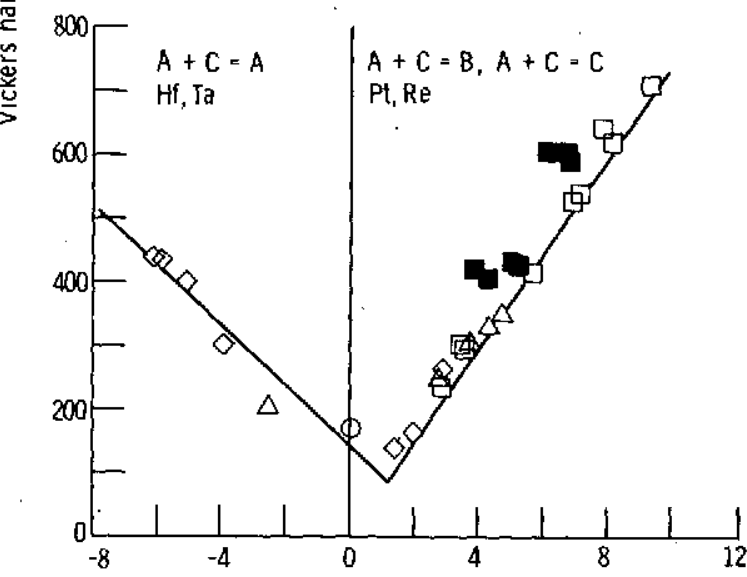

Electron concentration parameter, $\Omega=C^{1 / 2} \Delta V$

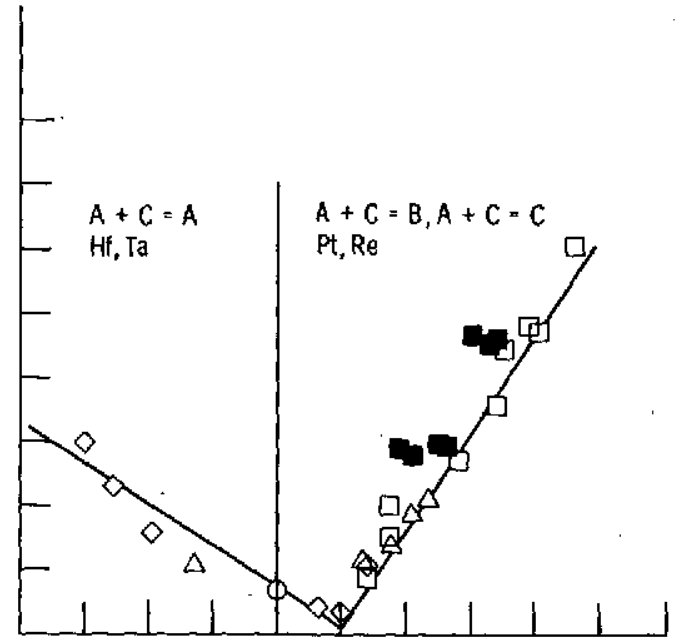

(b) $188 \mathrm{~K}$.

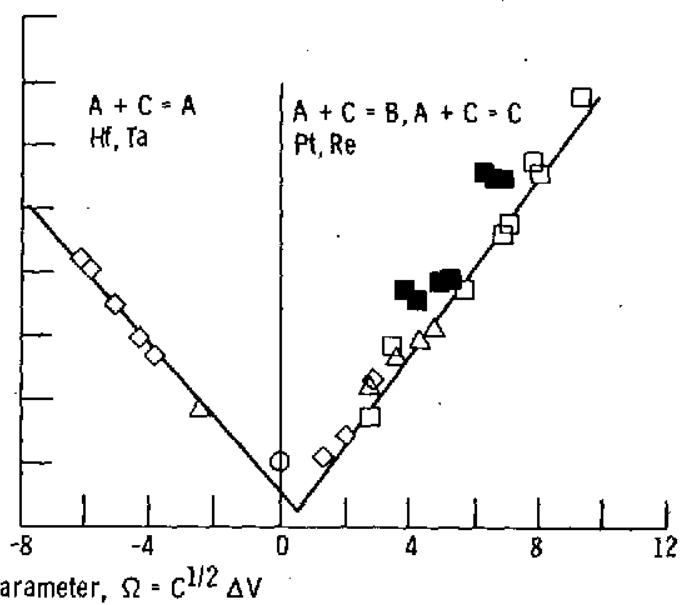

(d) $411 \mathrm{~K}$.

Figure 9. - Correlation of hardness of ternary Mo alloys, A + C combinations, with square root of individual solute content and difference in number of $s$ and d electrons. 

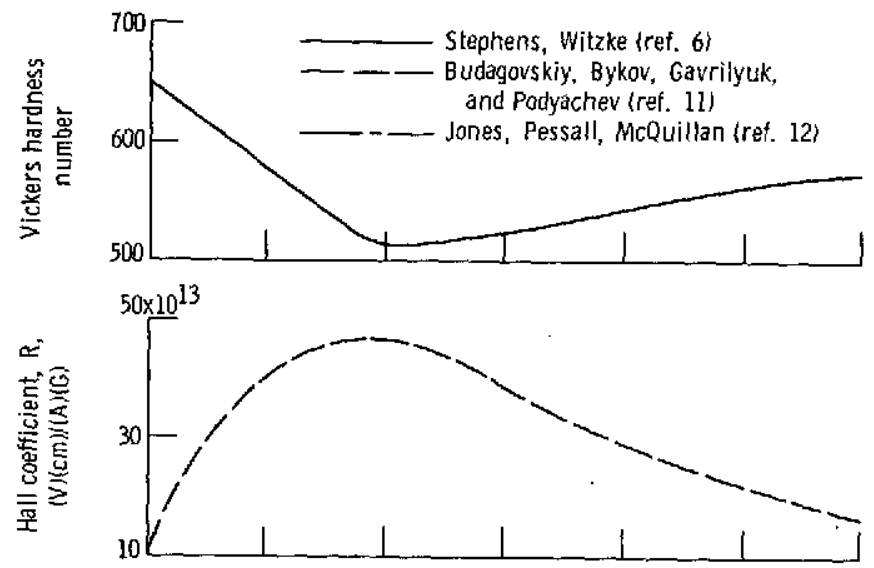

(a) W-Re alloys at $77 \mathrm{~K}$,
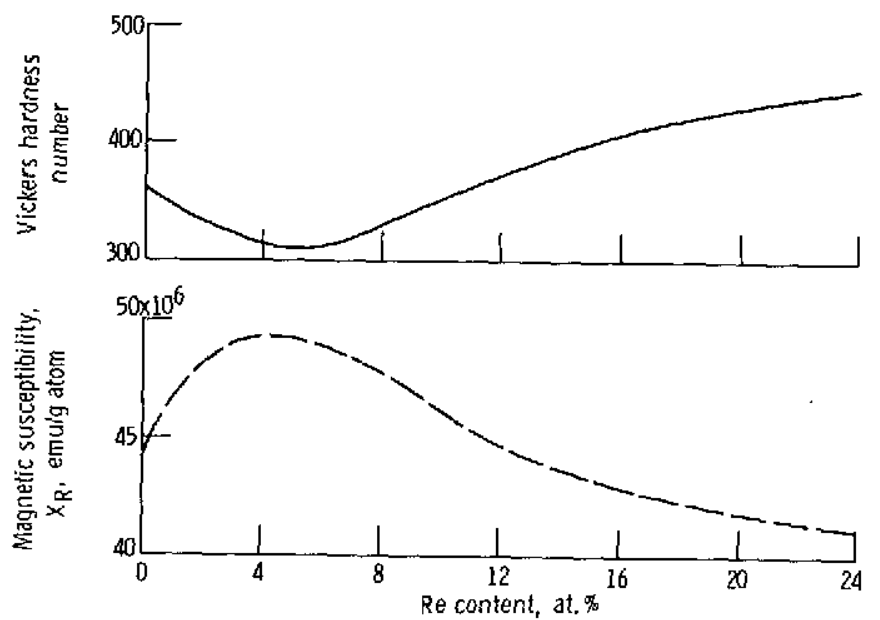

(b) W-Re alloys at $300 \mathrm{~K}$.
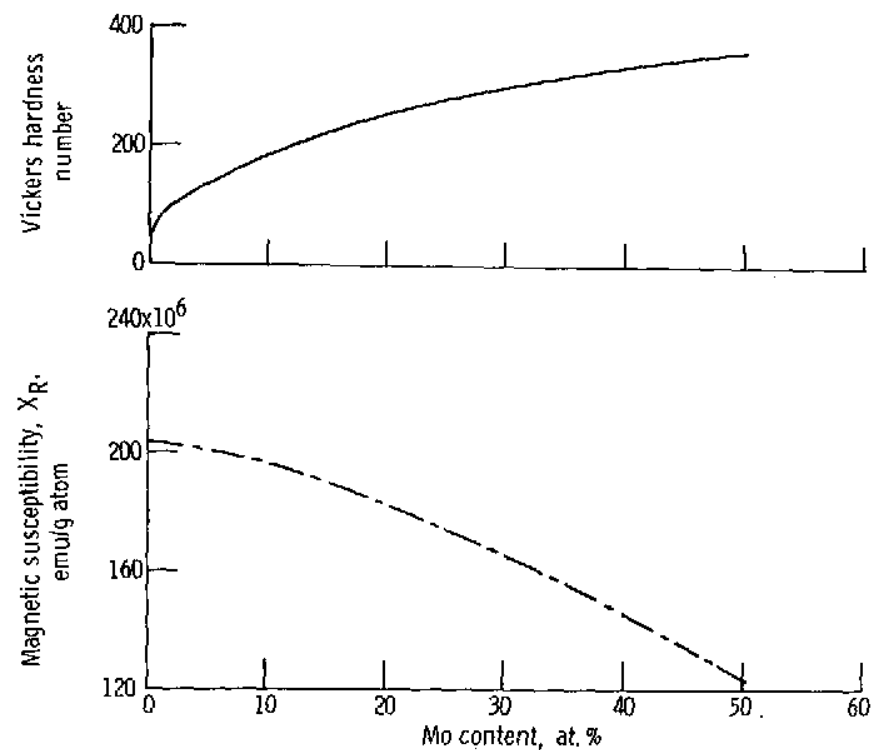

(c) $\mathrm{Nb}$-Mo alloys at $300 \mathrm{~K}$.

Figure 10. - Correlation of hardness of W-Re and Nb-Mo alloys with Hall coefficient and magnetic susceptibility measurements. 